\title{
Genetic variation associated with preterm birth: A HuGE review
}

Krista S. Crider, MA, $P h D^{1}$, Nedra Whitehead, MS, $P h D^{2}$, and Rebecca M. Buus, $P h D^{2}$

\begin{abstract}
Preterm birth (PTB) is a major public health concern because of its high prevalence, associated mortality and morbidity, and expense from both short-term hospitalization and long-term disability. In 2002, $11.9 \%$ of U.S. births occurred before 37 weeks gestation. Epidemiologic studies have identified many demographic, behavioral, and medical characteristics associated with PTB risk. In addition, recent evidence indicates a role for genetic susceptibility. We reviewed 18 studies published before June 1, 2004, that examined associations between polymorphisms in the maternal or fetal genome and PTB risk. Studies of a polymorphism in tumor necrosis factor- $\alpha$, a proinflammatory cytokine, showed the most consistent increase in the risk of PTB. Environmental factors such as infection, stress, and obesity, which activate inflammatory pathways, have been associated with PTB, suggesting that environmental and genetic risk factors might operate and interact through related pathways. This review highlights maternal and fetal genetic susceptibilities to PTB, the potential relationships with environmental risk factors, and the need for additional well-designed studies of this critical public health problem. Genet Med 2005:
\end{abstract} 7(9):593-604.

Key Words: preterm birth, genetic polymorphisms, TNF- $\alpha$, , IL6, IL4, IL1 $\beta$, ILRA, toll-like receptor-4, MMP1, MMP9, $\beta_{2} A R, V E G F$

Preterm birth (PTB) is a major public health concern because of its high prevalence, associated mortality and morbidity, and expense of hospitalization and long-term disability. In $2002,11.9 \%$ of all births and $10.4 \%$ of singletons were preterm, a $7 \%$ increase since $1990 .{ }^{1}$

Pregnancy and parturition involve a complex molecular and biologic interplay of mother and fetus, which is not well understood. These processes have yet to be fully elucidated, hindering efforts to understand and prevent PTB. In the absence of complete knowledge of pregnancy maintenance biology and labor initiation, efforts to prevent PTB have focused on identifying risk factors.

The strongest risk factors for PTB suggest a maternal or fetal genetic predisposition toward PTB. Women born preterm are more likely to deliver preterm. ${ }^{2}$ Approximately $20 \%$ of women who deliver preterm subsequently have another PTB with the same partner; changing partners reduces the risk by one

From the ${ }^{I}$ Division of Birth Defects and Developmental Disabilities; National Center on Birth Defects and Developmental Disabilities, Centers for Disease Control and Prevention; ${ }^{2}$ Division of Reproductive Health, National Center of Chronic Disease Prevention and Health Promotion, Centers for Disease Control and Prevention, Atlanta, Georgia.

Krista Stimson Crider, Ph.D., National Center on Birth Defects and Developmental Disabilities, Centers for Disease Control and Prevention, 1600 Clifton Road, Mail Stop E-86, Atlanta, GA 30333.

Received: June 24, 2005.

Accepted: September 9, 2005.

The findings and conclusions in this report are those of the author(s) and do not necessarily represent the views of the funding agency.

DOI: 10.1097/01.gim.0000187223.69947.db third. ${ }^{3,4}$ Twin studies of pregnancy outcome estimate the heritability of PTB as $17 \%$ to $36 \% .5,6$

Epidemiologic studies have identified other risk factors: maternal age less than 18 years or more than 35 years, ${ }^{7}$ underweight or overweight before pregnancy, ${ }^{8}$ and short stature. ${ }^{9}$ Black or African American women and women of low socioeconomic status consistently have higher rates of PTB. ${ }^{1,7}$ Physical stress, such as standing for long periods, increases PTB risk, ${ }^{5}$ and psychosocial stress has also been associated with higher preterm rates, although less consistently. ${ }^{10,11}$

Infections like chorioamnionitis may initiate preterm labor. Bacterial vaginosis $(\mathrm{BV})$ is associated with increased PTB risk even without infection of the fetal membranes. ${ }^{7}$ Increased inflammation occurs in normal parturition, and inflammatory cytokines are higher in women who deliver preterm. ${ }^{12}$ Infection, stress, and obesity are all known to promote inflammation, ${ }^{13,14}$ which suggests that these environmental exposures may promote an inflammation-mediated mechanism (Fig. 1) resulting in early parturition.

To establish and maintain a pregnancy, the immune response, which normally destroys foreign material, must make exception for the fetus. Promising research is elucidating some of the molecular mechanisms involved in this pregnancy-immune response. The immune system is composed of innate cellular responses; pregnancy affects both. The innate immune response involving monocytes, granulocytes, mast cells, natural killer cells, complement and acute phase proteins ${ }^{15}$ is responsible for mounting an immediate response to pathogens. The cellular immune response, responsible for a slower but highly specific and sustained antiantigen response, is com- 


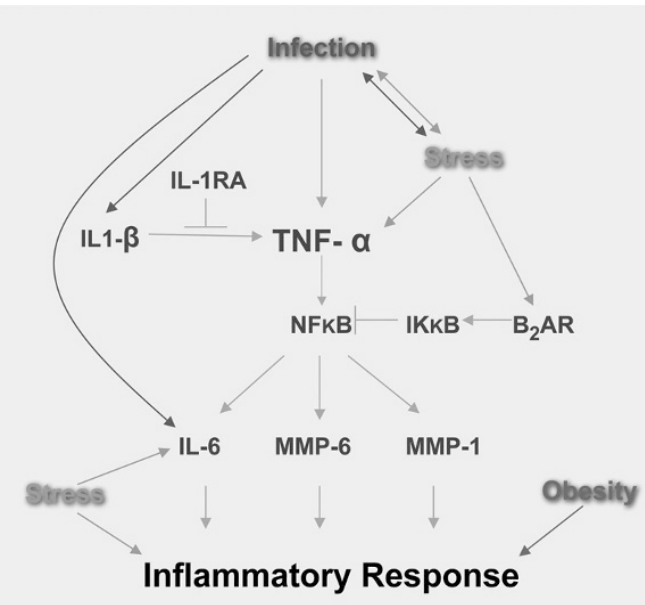

Fig. 1. Pathways to the inflammation response. Interactions of gene products and environmental exposures discussed in this review. Environmental exposures such as obesity, infection, and stress (hypothalamic-pituitary-adrenal axis activation from psychosocial and physiologic sources) induce inflammatory pathways. Many of these interact through tumor necrosis factor alpha (TNF- $\alpha$ ). TNF- $\alpha$ induces activation of nuclear factor kappa-B $(\mathrm{NF} \kappa \mathrm{B})$, a transcription factor that induces matrix metalloproteinase expression and extracellular matrix degradation. These pathway members are involved in various feedback loops not included in this figure, and their regulation can increase or decrease inflammatory response.

posed of $\mathrm{T}$ and $\mathrm{B}$ cells and antibody production..$^{15}$ In the adaptive immune response, $T$ cells are inhibited. Some women with T-cell-mediated autoimmune diseases such as rheumatoid arthritis go into remission during pregnancy. ${ }^{16,17}$ However, Bcell-mediated autoimmune diseases such as lupus worsen during pregnancy. ${ }^{18}$ Normal pregnancy is characterized by a reduction in the proinflammatory cytokine, TNF- $\alpha$, as well as type 1 cytokines, interferon- $\gamma$ and interleukin (IL)2, and increases in type 2 cytokines, IL4, IL5, and IL10. ${ }^{19}$ Some components of the innate immune response, including IL12 and IL1 $\beta$, are activated. ${ }^{20}$ PTB before 32 weeks of gestation is associated with infection or inflammation; ${ }^{21-23}$ therefore, polymorphisms in genes regulating the adaptive or innate immune system might alter pregnancy-immune response and affect parturition timing.

Researchers have begun to investigate the effects of candidate gene polymorphisms on PTB, focusing on polymorphisms related to inflammatory and immune response because of the evidence of the involvement of inflammation in pregnancy and parturition. We review studies published before June 1, 2004, that examine the association between PTB and polymorphisms in the maternal or fetal genome.

\section{METHODS}

PubMed and OVID were searched using the following keywords: preterm birth, preterm delivery, prematurity, premature birth, premature delivery, in combination with: polymorphism, genetic, allele, genetic polymorphism, TNF- $\alpha$, IL6, IL4, IL1 $\beta$, IL1-RA, IL-1RN, IL1RA, toll-like receptor-4, TLR4, MMP1, MMP9, $\beta 2 A R$, VEGF, and MTHFR. Publications were included if they examined maternal or fetal genetic variations having direct association with PTB or preterm premature rupture of the membranes (PPROM).

\section{INFLAMMATORY CYTOKINES ASSOCIATED WITH PRETERM BIRTH}

Cytokines are a large class of soluble molecules used in intercellular and intracellular communication that can increase and decrease the inflammatory response. The following section reviews studies of polymorphisms in inflammatory cytokines and PTB.

\section{Tumor necrosis factor- $\alpha$}

\section{Regulation and function}

TNF- $\alpha$ is a proinflammatory cytokine with multiple roles in the immune response, including rapid defense infection. Regulation of this inflammatory response includes positive feedback loops, which can allow the response to escalate, resulting in the pathology of autoimmune disease. Anti-TNF- $\alpha$ drugs are used to control symptoms of autoimmune diseases such as Crohn disease, psoriasis, and rheumatoid arthritis by inhibiting this inflammation response. ${ }^{24}$

TNF- $\alpha$ is involved in remodeling the cervix and fetal membranes by promoting production of collagen-degrading matrix metalloproteinases (MMPs), including MMP1 and MMP9 (Fig. 1).25 Monzon-Bordonaba et al. proposed that TNF- $\alpha$ functions as a mediator of pregnancy establishment and maintenance, and of normal and premature rupture of membranes (PROM) through its modulation of trophoblasts. ${ }^{26}$ In this model, TNF- $\alpha$ under normal physiologic conditions induces trophoblast differentiation, invasion and adhesion, implantation, placental development, and fetal membrane growth and remodeling. ${ }^{26}$ TNF- $\alpha$ secreted in early pregnancy encourages implantation; however, it can also trigger adverse events. Alterations in TNF- $\alpha$ levels can trigger endocrine function inhibition, protease activation, and extracellular matrix degradation resulting in pregnancy failure if misregulation occurs early in pregnancy, or PPROM and PTB if misregulation occurs later in pregnancy. ${ }^{26}$

TNF- $\alpha$ is produced in an insoluble pro-form. Once the proform is cleaved by TNF- $\alpha$-converting enzyme, TNF- $\alpha$ is secreted and the systemic effects are observed. ${ }^{27}$ Because of this type of protein regulation, the effects of TNF- $\alpha$ up-regulation might not be observed until after stimulation from infection or other environmental factors activating the cleavage mechanism.

Several gene polymorphisms within the TNF sequence are known. Herman et al. ${ }^{28}$ identified five polymorphisms at positions $-857,-851,-308,-232$, and +691 , and Kamizono et al. ${ }^{29}$ identified three single nucleotide polymorphisms (SNPs) in which adenine is substituted for guanine in the upstream region of $T N F$, designated as $-238 \mathrm{G} /-238 \mathrm{~A},-308 \mathrm{G} /-308 \mathrm{~A}$, and $-376 \mathrm{G} /-376 \mathrm{~A}$. The $T N F(-308 \mathrm{~A})$ allele $(\mathrm{TNF} 2$ or TNFA2) is located in the promoter region of TNF. Individuals 
who have one or more copies of the TNF(-308A) allele produce slightly more TNF- $\alpha$ than those with two copies of the major alleles, ${ }^{30,31}$ although actual production varies in tissues and individuals. It has been suggested that individuals with the $T N F(-308 A)$ allele may hyper-respond to infections with increased expression of TNF- $\alpha$, and that these individuals have increased complications from infections such as sepsis, cerebral malaria, mucocutaneous leishmaniasis, and human papilloma virus. ${ }^{32-35}$

\section{Tumor necrosis factor(-308) maternal genotype studies}

Roberts et al. first reported an association between $T N F(-308 A)$ allele and PPROM in a case-control study of African American women ${ }^{36}$. Cases included 55 African American women who delivered before 37 weeks because of PPROM or idiopathic preterm labor. Exclusion criteria included multiple gestation and fetal anomalies. There were 110 control participants who delivered after 37 weeks with no history of PTB. No association with idiopathic PTB and the $T N F(-308 A)$ allele was found, but the power of the study may have been inadequate. There were significantly more carriers (homozygous and heterozygous) of the $\operatorname{TNF}(-308 \mathrm{~A})$ allele among preterm cases attributable to PPROM ( $\mathrm{N}=15 / 26$, $58 \%)$ than among controls $(\mathrm{N}=33 / 110,30 \%)$ (odds ratio $[\mathrm{OR}]=3.18,95 \%$ confidence interval $[\mathrm{CI}] 1.33-7.83 ; P=$ .008). The carrier rate among controls was consistent with that reported in other studies. ${ }^{37,38}$

Another case-control study designed to look for an association between cytokine polymorphisms, periodontal disease, and PTB. The authors found that cytokine polymorphisms were not associated with periodontal disease, but the $\operatorname{TNF}(-308 \mathrm{~A})$ allele was positively associated with PTB. ${ }^{39}$ Of the participants who delivered preterm, $48 \%(\mathrm{~N}=23 / 48)$ possessed the $-308 \mathrm{~A}$ allele versus $29 \%(\mathrm{~N}=24 / 82)$ of the controls $(\mathrm{OR}=2.2,95 \% \mathrm{CI} 1.0-5.0, P=.026)$. The cases included women who delivered prematurely as the result of preterm labor or PPROM. The study population consisted of multiple racial groups.

An early study by Dizon-Townson et al. found no significant variation between the frequencies of $\operatorname{TNF}(-308 \mathrm{~A})$ allele in women who delivered preterm $(\mathrm{N}=203)$ compared with controls $(\mathrm{N}=41),{ }^{40}$ but the controls were unselected for medical or obstetric history. In a later article, the author stated that a reanalysis limited to infection-related PTBs found a trend toward significance. ${ }^{41}$

These studies support a possible correlation between maternal TNF (-308A) allele and PTB. Neither study that found an association between TNF $(-308 \mathrm{~A})$ and PTB assessed the infant's genotype. ${ }^{36,39}$

\section{TNF(-308) fetal genotype studies}

Fetal tissues also produce TNF- $\alpha$. Aidoo et al. found that infant genotype correlated with increased PTB risk in a cohort study of 1048 singleton infants in Western Kenya. ${ }^{42}$ This study was designed to examine immunologic variation to malaria infection rather than PTB risk. The large study allowed analysis of both homozygotic ( $\mathrm{N}=19 / 1048,1.8 \%)$ and heterozygotic infants $(\mathrm{N}=160 / 1048,15 \%)$. Both the TNF $(-308 A)$ homozygous genotype (relative risk $=7.3,95 \%$ CI $2.85-18.9$ ) and the heterozygous genotype (relative risk $=6.7,95 \%$ CI $2.0-23$ ) were significantly associated with PTB. Maternal TNF(-308) genotype was not ascertained.

Chen et al. examined the association between the $T N F(-308 A)$ allele and PTB risk in a Chinese population with a matched case-control study of familial triads (mother, father, and infant) of 54 case infants and 79 control infants. ${ }^{43}$ Cases were live singleton births more than 28 but less than 37 weeks gestation without regard to birth weight. Control infants were matched for ethnicity, age, and delivery date. Multiple logistic regression models found that the OR for PTB was 1.77 (95\% CI $0.75-4.2)$ among $T N F(-308 A)$ heterozygotes and 12.1 (95\% CI 1.4-128.7) among homozygous infants. Matching was accounted for in the analysis. No association was found for the genotype of either parent.

The majority of studies showed a strong association between the TNF $(-308)$ genotype and PTB, suggesting that genetic differences for inflammatory response might affect pregnancy length. One study found that the $T N F(-308 A)$ allele was not associated with PTB in women with cervical incompetence, a condition excluded from the case definition of most of the PTB studies in this review. ${ }^{44}$ Although there are well-documented racial disparities in the rates of $\mathrm{PTB}$, there was no variation in the $\operatorname{TNF}(-308 \mathrm{~A})$ allele frequency between whites and African Americans in North Carolina. ${ }^{45}$ (The race and ethnicity classification/terminology used in the text of this review reflects the terminology used in the original referenced article.)

\section{Interleukin-1 gene complex polymorphisms}

\section{Regulation and function}

IL $1 \beta$ is another proinflammatory cytokine involved in pregnancy. In primate pregnancy, IL1 $\beta$ infuses into the amniotic cavity, resulting in TNF- $\alpha$ and prostaglandin production and increased uterine activity. ${ }^{46}$ IL1 $\beta$ and IL1 receptor antagonist (IL1RA; gene name: IL1RN) compete to bind the IL1 receptor. Thus, IL1RA can inhibit IL1 $\beta$-induced inflammation and labor (Fig. 1). ${ }^{47-49}$ A genetic variation of IL1RN, IL1RA ${ }^{\star} 2$ (a penta-allelic 86-base pair tandem repeat-variable number tandem repeat (VNTR) in intron 2), reduces production of IL1RA, increasing the inflammatory response length and severity ${ }^{50}$ Patients with rheumatoid arthritis who have the IL1RA ${ }^{*}$ allele combined with other variations in the inflammation pathway are less likely to respond to etanercept, a TNFblocking agent. ${ }^{51}$

\section{Interleukin-1 $\beta$ receptor antagonist and preterm birth}

A case-control study of 52 singleton pregnancies delivered before 34 weeks and 197 control pregnancies delivered after 37 weeks was examined for an IL1 $\beta$ polymorphism and IL1RA ${ }^{*} .{ }^{52}$ Cases were excluded for human immunodeficiency virus infection, history of cervical incompetence, known uterine abnormalities, fetal anomalies, and abruption 
of the placenta. Controls were excluded for previous PTB or cervical incompetence, fetal abnormalities, complicated antepartum course, and chorioamnionitis. Of the cases, 36.6\% were Europeans, $36.5 \%$ were non-African Hispanics, and 26.9\% were African Americans; the distribution of controls was $59.4 \%, 26.9 \%$, and $13.7 \%$, respectively. Among the Hispanic infants, the IL1RA 2 allele was associated with an increased risk for PROM and subsequent PTB (OR $=6.5,95 \%$ CI 1.25-37.7; $P=.021$ ), and for PTB overall. ${ }^{52}$ The carrier rate of IL1RA ${ }^{\star} 2$ allele was higher among Hispanic mothers who delivered preterm $(57 \%$ vs. $26.4 \% P=.028)$. The IL1RA ${ }^{\star} 2$ allele frequency among the women who delivered at term differed by race: $7.4 \%$ in women of African descent versus $27.4 \%$ $(P=.002)$ in women of European descent and $41.5 \%(P=$ $.004)$ in women of Hispanic descent. The effect of this allele may have been found only among Hispanics because of the higher prevalence of polymorphism in that population or they may have other immune system polymorphisms that amplify the effects of the IL1RA ${ }^{\star} 2$ polymorphism.

The IL1RA ${ }^{\star} 2$ allele was also associated with PTB and neonatal mortality in a case-control study of multifetal pregnancies. ${ }^{53}$ Multifetal pregnancies provide a natural experiment for observing the effect of multiple copies of a gene. In a study of 51 mothers (45 white, 3 Hispanic, and 3 Asian) and 104 neonates by Kalish et al., the median gestational age at delivery was 37 weeks (range 28-38 weeks). As expected, the IL1RA ${ }^{\star} 1$ allele (major allele) was more than twice as prevalent as IL1RA ${ }^{\star} 2$ allele. ${ }^{53}$ Fifty percent $(\mathrm{N}=12 / 24)$ of pregnancies in which both fetuses carried the IL1RA ${ }^{\star} 2$ allele, but only $11 \%(\mathrm{~N}$ $=3 / 27$ ) in which only one or no fetus carried the IL1RA ${ }^{\star} 2$ allele, were complicated by PPROM (OR $=8.0,95 \%$ CI $1.6-$ $50.3 P=.005)$. A greater percentage of control twin pairs were both homozygous for the major allele IL1RN ${ }^{\star} 1,44.4 \%(\mathrm{~N}=$ $16 / 36)$ versus $6.7 \%(\mathrm{~N}=1 / 15)$ of the PPROM cases $(\mathrm{OR}=$ 11.2, 95\% CI 1.3-70.1; $P=.010$ ). However, infant genotype analysis may be confounded by zygosity, which was not determined. Also, no information on fertility treatments was given. Maternal genotype was not related to pregnancy outcome in this small study.

In a prospective cohort study of 291 consecutive singleton pregnancies undergoing amniocentesis at 15 to 17 weeks gestation, Witkin et al. found that fetal homozygosity for IL1RA 2 allele was significantly associated with birth before 37 weeks gestation $(P<.0001),{ }^{54}$ although only 18 women delivered preterm. The study took place in Switzerland, and all participants were of European descent. The allelic distribution was in Hardy-Weinberg equilibrium. The population used for this study is problematic, however, because many indications for amniocentesis are also associated with an increased risk of PTB risk.

\section{Interleukin-6}

\section{Regulation and function}

IL6, generally considered a proinflammatory cytokine, can induce the acute phase inflammatory response by inducing $\mathrm{T}$ lymphocytes, $\mathrm{C}$ reactive protein, and B cell differentiation. IL6 concentrations are increased in the amniotic and cervical fluid and maternal serum of preterm deliveries. ${ }^{55-57} \mathrm{~A}$ polymorphism in the IL6 gene at position -174 ( $\mathrm{G}$ to C) reduces IL6 production, the severity and onset of juvenile chronic arthritis, and kidney transplant rejection, and is associated with improved outcomes in high-risk patients with breast cancer. ${ }^{58-60}$ One study investigated whether this polymorphism also reduces PTB risk. ${ }^{61}$

\section{Interleukin-6 (-174) and preterm birth}

Simhan et al. examined the polymorphism distribution among 156 women who delivered after 37 weeks of gestation (110 white, 46 African American) and 51 women who delivered before 34 weeks with spontaneous preterm labor and intact membranes (39 white, 12 African American). ${ }^{61}$ Women with preeclampsia, diabetes, vaginal bleeding, collagen disease, and cervical cerclage were excluded. Overall, $19.2 \%$ of the controls and $2 \%$ of the cases $(\mathrm{OR}=0.17,95 \%$ CI $0.04-0.74)$ were homozygous for the IL6 $(-174 \mathrm{C} / \mathrm{C})$ variant. Among whites, the $\mathrm{C}$ variant was found in $27.2 \%$ of the controls and $5.2 \%$ of cases $(\mathrm{OR}=0.14,95 \% \mathrm{CI} 0.03-0.64)$. No African Americans carried the protective $\mathrm{C} / \mathrm{C}$ genotype.

A number of studies have shown that the distribution of IL6 polymorphisms differs among racial groups. African American and Asian populations have polymorphisms that increase IL6 expression levels, whereas the IL6 $(-174 \mathrm{C})$ allele, which reduces IL6 production, is more common among whites. ${ }^{62}$ In a North Carolina population, the frequency of IL6 (-174C/C) homozygotes was significantly higher among whites (15\%) than African Americans (2\%). ${ }^{45}$ Of whites, $35 \%$ were heterozygous or homozygous for the IL6 (-174C) allele, whereas $9 \%$ of African Americans were heterozygous and none were homozygous. ${ }^{59}$

\section{Interleukin-4}

\section{Regulation and function}

IL4 is a potent cytokine produced by $\mathrm{TH}_{2}$ lymphocytes and involved in innate immunity. IL4 induces differentiation of B lymphocytes and blocks production of interferon- $\gamma$, thereby reducing proinflammatory cytokines such as TNF- $\alpha$, IL6, and IL1. IL4 levels increase during the course of normal pregnancy. ${ }^{63}$ A polymorphism in the promoter region of IL4 at position -590 (C to T) is associated with increased severity of asthma and atopic dermatitis, ${ }^{64,65}$ but with a decreased risk of Graves disease. ${ }^{64}$ IL4 level variations seem to modulate the balance between innate and cellular immunity. Because cellular immunity is thought to be reduced and innate immunity increased during pregnancy, ${ }^{15}$ any variation in this balance might affect pregnancy outcome.

\section{Interleukin-4 and preterm birth}

Kalish et al. investigated the relationship between PTB in multifetal pregnancies and maternal and fetal IL4 and IL1O genotypes. ${ }^{66}$ The cohort study included 73 mother-infant 
pairs, 71 twin sets, and 2 triplets. Mothers included 61 white, 5 Hispanic, 3 African American, and 4 Asian women. Spontaneous PTB was defined as delivery for any reason before 37 weeks gestation, with or without PPROM. Exclusion criteria included delivery before 24 weeks gestation and pregnancies complicated by intrauterine fetal death. No association between the IL10 (-1082) polymorphism and PTB was found, but the IL4 $(-590 \mathrm{~T})$ allele in either the mother or infant was associated with increased PTB risk. The frequency of maternal heterozygosity for the IL4 (-590T) allele was significantly higher in women who delivered preterm than those who delivered at term, $36.2 \%$ versus $18.2 \%(\mathrm{OR}=2.6,95 \% \mathrm{CI} 1.1-5.9$; $P=.02$ ). Although $20.7 \%$ of women who had a PTB were homozygous for the IL4 (-590T) allele, only $2.3 \%$ of women who did not have a PTB were homozygous ( $\mathrm{OR}=11.2,95 \% \mathrm{CI}$ $1.2-69.5 ; P=.01)$. When the fetal genotypes were examined, $55.2 \%$ of preterm deliveries had two fetuses with the IL4 $(-590 \mathrm{~T})$ allele compared with only $29.5 \%$ of term deliveries $(\mathrm{OR}=2.9,95 \%$ CI $1.0-8.8 ; P<.05)$. The relationship between infant genotype and PTB may have been confounded by zygosity, which was not determined. This study suggested that the IL4 (-590T) allele may be a risk factor for PTB in multifetal pregnancies. The authors did not expect this finding because increased IL4 production occurs in healthy pregnancies, ${ }^{63}$ and because it reduces proinflammatory cytokines associated with increased PTB. As previously discussed, this polymorphism is associated with an increased risk of asthma and other immunoglobulin-E-mediated conditions, leading Kalish et al. to speculate that there may be a relationship between allergic disease and PTB. ${ }^{66}$ Alternatively, the authors suggest that the IL4 polymorphism predisposes individuals to severe infection and PTB through an infection-mediated mechanism. Also, the result may be an artifact of small sample size and potentially confounded by zygosity or assisted reproductive technology, a frequent cause of multifetal pregnancies.

\section{ADDITIONAL POLYMORPHISMS ASSOCIATED WITH PRETERM BIRTH}

\section{Matrix metalloproteinases}

\section{Regulation and function}

Fetal membrane rupture involves MMP-mediated interstitial collagen degradation. MMP1 is the first enzyme to catabolize fibroblast collagen, which is further broken down by gelatinases, MMP2, and MMP9. MMP polymorphisms are associated with coronary heart disease (MMP1), poor prognosis in breast cancer (MMP1), severe chronic periodontitis (MMP1), abdominal aortic aneurysm (MMP9), atherosclerosis (MMP9), and emphysema (MMP9). ${ }^{67-71}$

\section{Matrix metalloproteinase-1 and preterm birth}

MMP1 concentrations increase with gestational age and at parturition in normal pregnancies and in cases of PPROM. ${ }^{72-74}$ Fujimoto et al. examined the relationship between a $\mathrm{G}$ insertion $(2 \mathrm{G})$ allele in the promoter of $M M P 1$ at -1607 that had been shown to increase MMP1 expression ${ }^{75}$ with PPROM and PTB. ${ }^{76}$ They conducted a case-control study of African American singleton infants without induced labor or malformations. Pregnancies presenting with PPROM before 37 weeks were compared with term pregnancies with no history of PPROM and PTB. Rupture of membranes was diagnosed by vaginal fluid pooling and Nitrazine test. Infants from pregnancies complicated by PPROM had a significantly higher frequency of $1 \mathrm{G} / 2 \mathrm{G}$ heterozygotes and $2 \mathrm{G} / 2 \mathrm{G}$ homozygotes $(\mathrm{N}=$ $66 / 75 ; 88 \%)$ than did controls $(\mathrm{N}=179 / 235 ; 76.2 \%)(\mathrm{OR}=$ 2.29, 95\% CI 1.09-4.82; $P=.028)$. Conversely, the $1 \mathrm{G} / 1 \mathrm{G}$ polymorphism, which reduces MMP1 expression, protected against PPROM. In this study, 1G/1G homozygotes frequencies were higher among whites than African Americans. ${ }^{76}$

\section{Matrix metalloproteinase-9 and preterm birth}

MMP9 is involved in the degradation of the basement membrane and other extracellular matrix components and increases in humans at the time of parturition. ${ }^{74}$ MMP9 expression is induced in epithelial cells, monocytes, and macrophages ${ }^{77,78}$ by proinflammatory cytokines and bacterial endotoxins. Recent studies suggest that increased fetal levels of MMP9 are involved in PPROM and differentiate fetuses with PPROM from those undergoing premature labor with intact membranes. ${ }^{79}$ MMP9 promoter polymorphisms have been investigated as possible mechanisms of MMP9 overexpression and susceptibility to PPROM. Ferrand et al. designed a casecontrol study of African American women. ${ }^{80}$ Cases $(\mathrm{N}=74)$ were infants from pregnancies presenting before 37 weeks gestation with PPROM. Controls $(\mathrm{N}=215)$ were full-term infants whose mothers had no history of PPROM or PTB. Individuals were excluded because of multiple gestation, fetal abnormalities, and medical complications requiring labor induction. Rupture of membranes was diagnosed by vaginal fluid pooling and Nitrazine test. Cases and controls were genotyped to determine the CA repeat sequence length in the $M M P 9$ promoter and for a polymorphism at -1562 . No association was found for the -1562 polymorphism, but the $14 \mathrm{CA}$ repeat was associated with a significantly increased PPROM risk compared with all other repeat sizes (OR $=3.06,95 \% \mathrm{CI}$ 1.77-5.27), and with two to threefold more MMP9 expression than the 20 CA repeat size. The frequency of the 14 CA repeat in MMP9 is lower in the African American population than in whites, $19 \%$ versus $50 \% .80,81$

\section{Toll-like receptor 4}

\section{Regulation and function}

The toll-like receptor 4 (TLR4) is a transmembrane receptor involved in the innate immune response to Gram-negative bacteria. ${ }^{82}$ There are many known polymorphisms in this critical receptor. One allele, TLR4(Asp299Gly), has been associated with severe respiratory syncytial virus disease in infants and increased risk of Gram-negative bacterial infection in critically ill hospital patients. ${ }^{83,84}$ 


\section{Toll-like receptor 4 and preterm birth}

The relationship of the TLR4(Asp299Gly) allele with PTB was examined in a Finnish population. ${ }^{85}$ The study compared the genotypes of 351 term infants (maternal history of PTB was not mentioned as an exclusion criterion) with those of 440 infants of less than 35 weeks gestation (282 singletons and 158 multiples). They also genotyped 94 unrelated women (74 premature, 62 premature singleton, and 12 premature multiparous deliveries). ${ }^{85}$ The TLR4(Asp299Gly) and (Thr399Ile) polymorphisms exhibited linkage disequilibrium, so only one, (Asp299Gly), was chosen for further examination. The frequency of the TLR4(Asp299Gly) allele did not vary among the women, but there was a significant difference in the allele frequency between singleton term and preterm infants $(P=$ .024). The association was not significant when multiple births were included, which are not independent. The association of the allele was stronger with PPROM cases $(P=.021)$ than other causes of PTB $(P=.045)$.

\section{Beta-2-adrenergic receptor}

\section{Regulation and function}

Beta-2-adrenergic receptor $\left(\beta_{2} \mathrm{AR}\right)$ is a multifaceted receptor involved in linkage of the sympathetic nervous system and the immune system. $\beta_{2} \mathrm{AR}$ acts in the myometrium to relax muscle fibers at the time of birth, ${ }^{86}$ and $\beta_{2} \mathrm{AR}$ agonists have been used for more than 30 years to inhibit uterine contraction during preterm labor. ${ }^{87}$ Norepinephrine stimulation of $\beta_{2} \mathrm{AR}$ leads to antibody secretion, lymphocyte traffic, and cytokine production ${ }^{88-90}$. Norepinephrine activation of $\beta_{2} \mathrm{AR}$ receptor stabilizes IK $\kappa \mathrm{B}$ (inhibitor of the TNF- $\alpha$-induced transcription factor $\mathrm{NF} \kappa \mathrm{B}$ ) and thus reduces expression of $\mathrm{NF} \kappa \mathrm{B}$-induced genes such as $I L 6$ and $I L 1 \beta^{91}$ (Fig. 1). A few of the 19 known $\beta_{2}$ AR gene polymorphisms have been associated with nocturnal asthma (Gly-16), obesity (Gln-27), and physical activitydependent obesity risk ( $G l n-27) .{ }^{92-96}$ In vitro studies suggest that the $G \ln -27$ allele is more resistant to down-regulation by adrenergic agonists than the major allele $(G l u-27) .{ }^{97}$ The Arg16Gly (Gly-16) allele increases the desensitization of the receptor when it is stimulated and thus reduces the response to stimuli over time. Given the suggested role of $\beta_{2} \mathrm{AR}$ in $\mathrm{NF} \kappa \mathrm{B}$ regulation ${ }^{91}$, the Gly-16 allele might decrease inhibition of the proinflammatory response.

\section{Beta-2-adrenergic receptor and preterm birth}

Landau et al. compared the genotype distribution of the $\beta_{2} A R$ polymorphisms Gln27Glu (Glu-27) and Arg16Gly (Gly16) among Hispanic women. ${ }^{98}$ Cases $(\mathrm{N}=28)$ were women with singleton pregnancies and without chorioamnionitis, uterine malformation, drug use, or fetal abnormalities who spontaneously delivered before 37 weeks of gestation. Controls $(\mathrm{N}=251)$ had a singleton delivery after 37 weeks of gestation with no PTB history. Arg16Arg homozygosity was associated with a markedly reduced PTB risk; $4 \%$ of cases $(\mathrm{N}=1 / 28)$ versus $31 \%$ of controls $(\mathrm{N}=79 / 251)$ were homozygous for $\operatorname{Arg16}(\mathrm{OR}=0.08,95 \% \mathrm{CI} 0.01-0.58 ; P=.01)$. The Arg16Arg allele was significantly less frequent in the cases (29\%) compared with controls (50\%, $P=.002)$. No association was found between the Gln27Glu allele and PTB. Being homozygous for the Arg16Arg allele (major allele) seemed protective for PTB.

A case-control study by Ozkur et al. also examined the association of Gln27Glu and Arg16Gly polymorphisms with PTB. ${ }^{99}$ This small but well-designed study in a Turkish population examined 80 women who were admitted for preterm labor at 21 to 36 weeks gestation (determined by ultrasound), excluding women with PPROM, major bleeding, pre-existing hypertension, diabetes, kidney disease, obesity, serious maternal diseases, related parents, or uterine contractions before 20 weeks. Controls $(\mathrm{N}=76)$ were women who delivered after 37 weeks of gestation with no PTB history or any other previously mentioned exclusion criteria. Because all women resided in the same district and none were referral patients, this study approximates a population-based sample, unlike the hospital based studies. The Gln27Glu allele frequency was higher among cases than controls, 0.42 versus $0.26(\mathrm{OR}=2.14,95 \%$ CI 1.32-3.46; $P=.002$ ). Unlike the Landau et al. ${ }^{98}$ study, this study showed no significant associations for the Arg16Gly polymorphism. The conflict could be the result of different study populations (United States vs. Turkey), different exclusion criteria, or small sample size.

\section{Vascular endothelial growth factor}

\section{Regulation and function}

Vascular endothelial growth factor (VEGF) is a critical signaling molecule that regulates the growth of vascular structures (angiogenesis). It is the only known mitogen that acts on endothelial cells. ${ }^{100}$ There are a number of known polymorphisms in the VEGF gene including $-1879 \mathrm{G} / \mathrm{A},-1498 \mathrm{~T} / \mathrm{C}$, $-1190 \mathrm{G} / \mathrm{A},-1154 \mathrm{G} / \mathrm{A},-634 \mathrm{C} / \mathrm{G},-7 \mathrm{C} / \mathrm{T}$, and 936 C/T. ${ }^{101,102}$ A polymorphism at -634 ( $\mathrm{G}$ to $\mathrm{C}$ ) has been associated with increased serum levels of VEGF. ${ }^{101}$ Diabetic patients with the $-634 \mathrm{C}$ allele are more likely to develop the vascular disease nonproliferative diabetic retinopathy than those with the $-634 \mathrm{G}$ major allele (OR 3.20; 95\% CI 1.45-7.05; $P=.0046) .{ }^{101}$

\section{Vascular endothelial growth factor and preterm birth}

Papazoglou et al. examined the association of two polymorphisms VEGF(936C/T and $-634 G / C)$ with spontaneous PTB in a case-control study of 54 women with preterm deliveries and 79 women attending a menopause clinic who had at least two term births and no history of preterm labor or pregnancy loss. ${ }^{102}$ It should be noted that the control and case population may have been very different because the controls are taken from an entirely different population, menopausal women. All participants were of Greek ethnicity. The authors defined PTB in this study as cervical changes and regular contraction before 37 weeks gestation. The $\operatorname{VEGF}(-634 \mathrm{G} / \mathrm{C})$ allele was not associated with PTB, but homozygotes or heterozygotes for the 936 $C / T$ polymorphism were more likely to have $\mathrm{PTB}(\mathrm{OR}=2.05$, 95\% CI 1.37-3.06). 


\section{Methylene tetrahydrofolate reductase}

Methylene tetrahydrofolate reductase (MTHFR) is an enzyme involved in folate metabolism, which is critical to many cellular processes, including DNA replication and methylation. A MTHFR polymorphism at 677 (C to T) reduces activity of the protein and has been implicated in vascular disease, neural tube defects, and leukemia. ${ }^{103-105}$

\section{Methylene tetrahydrofolate reductase and preterm birth}

Lauszus et al. examined MTHFR (677C/T) and PTB in diabetic mothers. ${ }^{106}$ In this Danish cohort, 233 insulin-dependent diabetic women were recruited from the maternity ward and genotyped. Sixty-one women delivered preterm $(<37$ weeks gestation). Heterozygosity at the MTHFR 677 locus was not associated with PTB. It is possible that these study results may not be readily generalized to nondiabetic women.

\section{Factor 5}

Factor 5 is a critical component of blood coagulation in which alterations can result in hemorrhagic or thrombotic diathesis. A common mutation in Factor 5 (G1691A) is associated with pregnancy complications and venous thromboembolism. ${ }^{107-109}$

\section{Factor 5 and preterm birth}

Hao et al. used high-throughput genotyping approaches to identify haplotype blocks containing multiple SNPs in 31 candidate genes potentially related to PTB. ${ }^{110}$ The SNPs were in Hardy-Weinberg equilibrium. The study included 300 women who had PTB before 37 weeks, and 458 controls. ${ }^{110}$ Study participants were racially and ethnically diverse: African American participants included 193 cases and 260 controls, Hispanic participants included 58 cases and 137 controls, and white participants included 50 cases and 61 controls. A Factor 5 haplotype was associated with PTB with a significance of $P=.025$, using haplotype-based association tests, 1000 permutation iterations, and Bonferroni correction. However, it is not clear how the haplotype affects coagulation. Some haplotypes that were not associated with PTB in the global model were associated with PTB among specific racial groups: ILR2 among African Americans ( $P=.025)$, NOS2A (inducible nitric oxide synthase) among whites $(P<.001)$, and OPRM1 (mu-opioid receptor) among Hispanics $(P=.004)$, but it is unclear whether these associations were significant after multiple test adjustment. Only maternal genotypes were examined, and interactions among genotypes and environmental factors were not considered.

\section{CONCLUSIONS AND RECOMMENDATIONS}

PTB likely involves multiple environmental and genetic risk factors. Many women delivering preterm have no known risk factors, and most interventions fail to substantially reduce risk. Therefore, expanding our knowledge of PTB risk and causality is critical to the discovery and implementation of effective intervention and treatment.

The studies reviewed here are the first steps in examining the association between genetic variation and PTB risk. However, the samples are generally small and are frequently convenience samples of high-risk populations at referral hospitals. The definition and measurement of the study outcomes are varied, and were generally not designed to examine the gene-gene and gene-environment interactions associated with PTB risk. Extensive replication along with information on racial/ethnic groups and subgroup analysis is needed before the impact of individual polymorphisms on PTB can be assessed, but results to date are intriguing.

Most studies described here found that maternal or fetal carriage of common polymorphisms in the inflammation pathway were associated with PTB risk. Generally, polymorphisms that increase the magnitude or duration of the inflammatory response (Table 1) were associated with increased PTB, and polymorphisms that decrease the response were associated with decreased PTB. This relationship concurs with epidemiologic evidence suggesting that environmental factors that increase inflammation also increase PTB risk. ${ }^{13,14,111}$

The $\operatorname{TNF}(-308 \mathrm{~A})$ allele was examined most frequently, and in most studies it was associated with increased PTB. Two studies suggest biologic mechanisms for this association. Hernandez-Guerrero et al. ${ }^{112}$ demonstrated that in vitro amniochorion tissue with the $\mathrm{TNF}^{\star} 2 / \mathrm{TNF}(-308 \mathrm{~A})$ allele responded similarly to lipopolysaccharide (surface lipopolysaccharide on Gram-negative bacteria, which triggers an immune reaction) as the major allele, except at higher lipopolysaccharide doses. The tissue with the $\operatorname{TNF}(-308 \mathrm{~A})$ allele produced significantly higher levels of TNF- $\alpha$ than the tissue with the major allele. This suggests that tissues expressing $T N F(-308 A)$ may hyperrespond to a uterine infection by releasing large amounts of TNF- $\alpha$. Simhan et al. found that maternal $\operatorname{TNF}(-308 \mathrm{~A})$ allele in term pregnancies increased the risk of chorioamnionitis by 3.3fold $(95 \% \mathrm{CI} ; 1.3-7.1),{ }^{38}$ suggesting that the $\operatorname{TNF}(-308 \mathrm{~A})$ allele might also be involved in infection-mediated PTB.

Recently, Macones et al. found that the $\operatorname{TNF}(-308 \mathrm{~A})$ allele was associated with increased PTB (OR $=2.7,95 \% \mathrm{CI}$ $1.7-4.5),{ }^{113}$ and that the association was even stronger in the presence of $\mathrm{BV}(\mathrm{OR}=6.1,95 \% \mathrm{CI} 1.9-21.0)$. In an accompanying review, Romero and colleagues hypothesized that BV might predispose women with a certain combination of polymorphisms to PTB, and that many polymorphisms may be involved in promoting a hyperimmune or hypoimmune response. ${ }^{114}$ In general, the studies reviewed here are consistent with this model, and there may be many additional multifactorial gene-gene and gene-environment interactions that produce a hyperimmune or hypoimmune responses that could lead to PTB (Fig. 1).

If TNF $(-308 \mathrm{~A})$ allele is found to promote PTB by oversecretion of TNF- $\alpha$, high-risk women could be treated with antiTNF- $\alpha$ drugs. There is no evidence these drugs are embryotoxic or teratogenic, ${ }^{115}$ but thorough study would be necessary before they could be used for a pregnant population. 


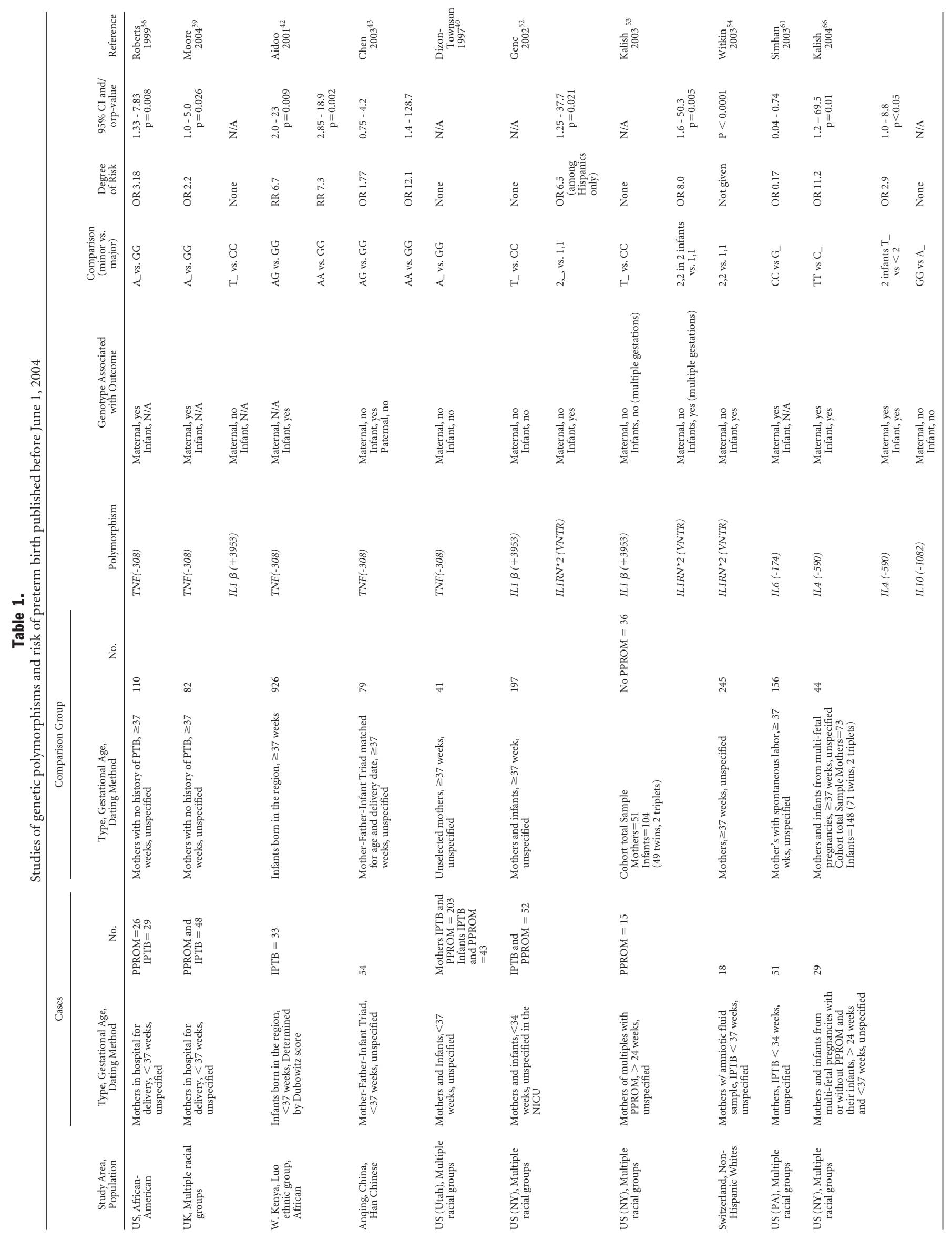




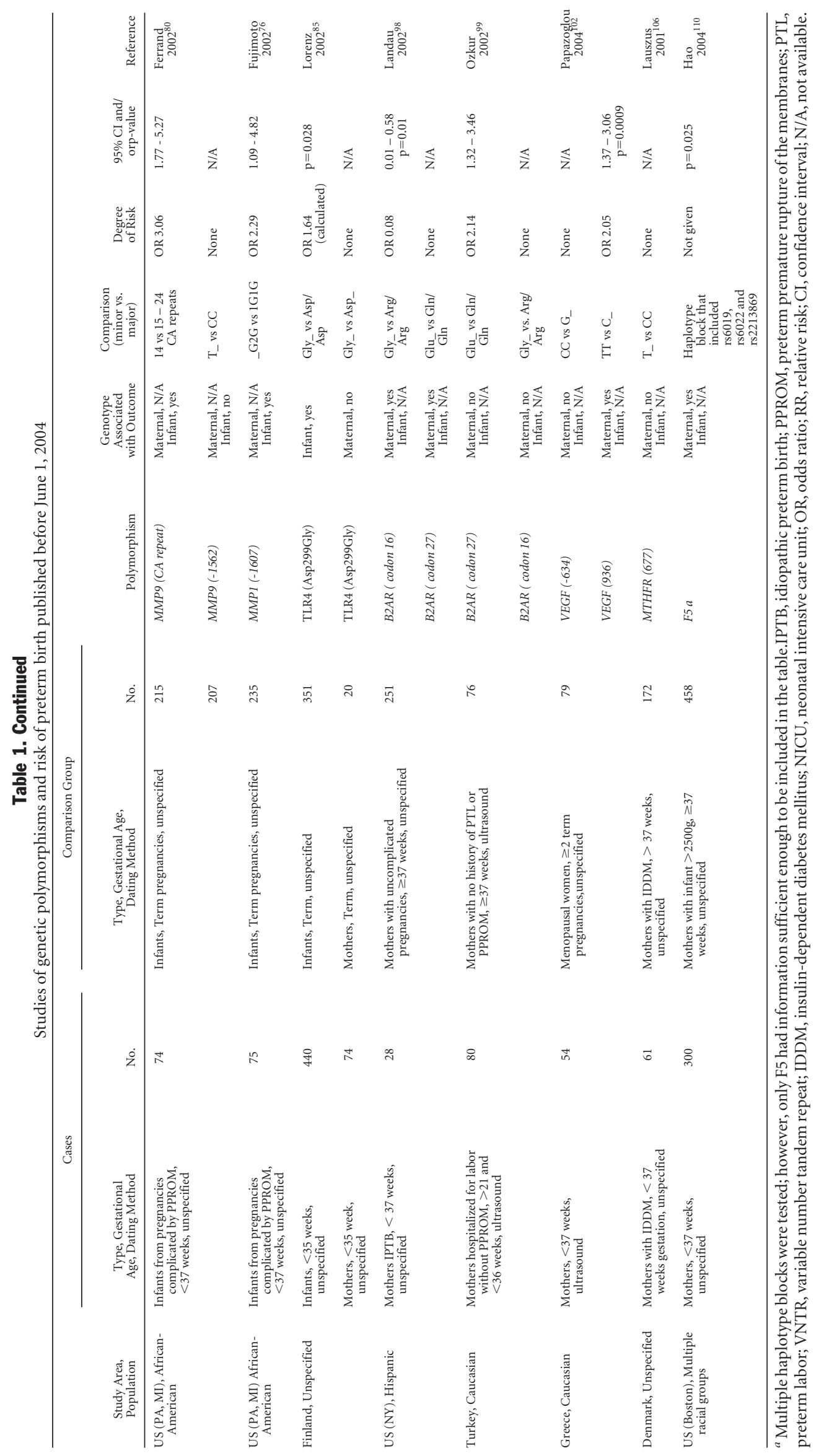




\section{Future studies}

Multiple interactions exist between the genes examined in this review (Fig. 1), suggesting that gene-gene interactions may affect PTB risk. For example, women who carry both the $T N F(-308 A)$ allele, which increases inflammation, and the IL6(-174C) allele, which reduces inflammation, may not be at increased PTB risk. Conversely, women who have both the $T N F(-308 A)$ allele and the IL1RA ${ }^{\star} 2$ allele might have a compounded risk of PTB. Therefore, a study of polymorphism combinations, in conjunction with modeling and analyses of maternal/fetal genotypes and phenotypes, would be valuable. Polymorphisms can be racially and ethnically distributed, so stratification is recommended.

Because many of the existing inflammation studies were based on small study populations not designed to examine gene-gene and gene-environment interactions in PTB risk, a large well-designed study would be invaluable. This study will need to model and analyze maternal/fetal genotypes and polymorphism combinations, phenotypes, sibling and parental health, and environmental exposures (infection, obesity, and stress). Such a study could easily be expanded to examine polymorphisms in other biologic systems that are important in pregnancy and parturition, such as placental vasculature development and hypothalamic-pituitary-adrenal axis regulation.

Researchers have focused on candidate genes in the inflammation pathway. In addition, pathways not yet discovered could be critical in PTB cause. Future studies could use whole genome scans to look for previously unidentified risk loci that confer an increased risk of PTB. Proteomic serum analysis could elucidate particular protein profiles that predict increased risk for PTB, and microarray-based expression studies could identify changes in gene expression between women who deliver preterm or at term. Successful use of any of these techniques requires consistent and specific case definitions, large sample size, and analysis of interactions between multiple factors.

\section{Preclinical and predictive impact}

In the future, genetic polymorphisms alone or in combination with information on environmental exposures may be useful in screening women for PTB susceptibility. To date, however, interventions for preventing PTB or treating preterm labor, such as antibiotics to treat infection or social support to offset the effects of stress, have been largely unsuccessful. ${ }^{7}$ Tocolytic agents do not consistently stop labor, ${ }^{116}$ and antibiotic administration has had conflicting results, and in some cases may worsen prognosis. ${ }^{117,118}$ However, recent progesterone prophylaxis trials have had promising results. ${ }^{19,120}$ These and other emerging interventions and treatments might improve outcomes in the future.

\section{CONCLUSION}

The studies reviewed here suggest that polymorphisms in inflammatory pathway genes may modulate a woman's PTB risk. Additional large and well-designed studies may show the critical genetic and environmental factors necessary to predict PTB risk. Genetic screening may someday be used to locate women at highest risk for preterm delivery, and to develop tailored interventions based on that woman's particular inflammatory tendencies, stress susceptibilities, vascular insufficiencies, or tissue-remodeling predisposition. Future research is needed to develop the tools to enable PTB risk prediction and assist in the development of targeted treatments to alleviate this major public health problem.

\section{References}

1. Martin JA, Hamilton BE, Sutton PD, Menacker F, et al. Births: final data for 2002. Natl Vital Stat Rep 2002;52:65-69.

2. Porter TF, Fraser AM, Hunter CY, Ward RH, et al. The risk of preterm birth across generations. Obstet Gynecol 1997;90:63-67.

3. Bakketeig LS, Hoffman HJ, Harley EE. The tendency to repeat gestational age and birth weight in successive births. Am J Obstet Gynecol 1979;135:1086-1103.

4. Li DK. Changing paternity and the risk of preterm delivery in the subsequent pregnancy. Epidemiology 1999;10:148-152.

5. Treloar SA, Macones GA, Mitchell LE, Martin NG. Genetic influences on premature parturition in an Australian twin sample. Twin Res 2000;3:80-82.

6. Clausson B, Lichtenstein P, Cnattingius S. Genetic influence on birthweight and gestational length determined by studies in offspring of twins. BJOG 2000;107:375381.

7. Slattery MM, Morrison JJ. Preterm delivery. Lancet 2002;360:1489-1497.

8. Cnattingius S, Lambe M. Trends in smoking and overweight during pregnancy: prevalence, risks of pregnancy complications, and adverse pregnancy outcomes. Semin Perinatol 2002;26:286-295.

9. Kramer MS, Coates AL, Michoud MC, Dagenais S, et al. Maternal anthropometry and idiopathic preterm labor. Obstet Gynecol 1995;86:744-748.

10. Barnes DL, Adair LS, Popkin BM. Women's physical activity and pregnancy outcome: a longitudinal analysis from the Philippines. Int J Epidemiol 1991;20:162172.

11. Austin MP, Leader L. Maternal stress and obstetric and infant outcomes: epidemiological findings and neuroendocrine mechanisms. Aust N Z J Obstet Gynaecol 2000;40:331-337.

12. Keelan JA, Blumenstein M, Helliwell RJ, Sato TA, et alCytokines, prostaglandins and parturition-a review. Placenta 2003;24(Suppl A):S33-S46.

13. Seematter G, Binnert C, Martin JL, Tappy L. Relationship between stress, inflammation and metabolism. Curr Opin Clin Nutr Metab Care 2004;7:169-173.

14. Lyon CJ, Law RE, Hsueh WA. Minireview: adiposity, inflammation, and atherogenesis. Endocrinology 2003;144:2195-2200.

15. Luppi P. How immune mechanisms are affected by pregnancy. Vaccine 2003;21: 3352-3357.

16. Da Silva JA, Spector TD. The role of pregnancy in the course and aetiology of rheumatoid arthritis. Clin Rheumatol 1992;11:189-194.

17. Ostensen M, Villiger PM. Immunology of pregnancy-pregnancy as a remission inducing agent in rheumatoid arthritis. Transpl Immunol 2002;9:155-160.

18. Meyer O. Making pregnancy safer for patients with lupus. Joint Bone Spine 2004; 71:178-182.

19. Elenkov IJ, Chrousos GP. Stress hormones, proinflammatory and antiinflammatory cytokines, and autoimmunity. Ann N Y Acad Sci 2002;966:290-303.

20. Luppi P, Haluszczak C, Betters D, Richard CA, et al. Monocytes are progressively activated in the circulation of pregnant women. J Leukoc Biol 2002;72:874-884.

21. Andrews WW, Hauth JC, Goldenberg RL. Infection and preterm birth. Am J Perinatol 2000;17:357-365.

22. Andrews WW. Cervicovaginal cytokines, vaginal infection, and preterm birth Am J Obstet Gynecol 2004;190:1179.

23. Goldenberg RL, Hauth JC, Andrews WW. Intrauterine infection and preterm delivery. N Engl J Med 2000;342:1500-1507.

24. Reimold AM. New indications for treatment of chronic inflammation by TNFalpha blockade. Am J Med Sci 2003;325:75-92.

25. So T, Ito A, Sato T, Mori Y, et al. Tumor necrosis factor-alpha stimulates the biosynthesis of matrix metalloproteinases and plasminogen activator in cultured human chorionic cells. Biol Reprod 1992;46:772-778.

26. Monzon-Bordonaba F, Vadillo-Ortega F, Feinberg RF. Modulation of trophoblast function by tumor necrosis factor-alpha: a role in pregnancy establishment and maintenance? Am J Obstet Gynecol 2002;187:1574-1580. 
27. Mezyk R, Bzowska M, Bereta J. Structure and functions of tumor necrosis factoralpha converting enzyme. Acta Biochim Pol 2003;50:625-645.

28. Herman C, Chernajovsky Y. Mutation of proline 211 reduces shedding of the human p75 TNF receptor. J Immunol 1998;160:2478-2487.

29. Kamizono S, Yamada A, Higuchi T, Kato H, et al. Analysis of tumor necrosis factor-alpha production and polymorphisms of the tumor necrosis factor-alpha gene in individuals with a history of Kawasaki disease. Pediatr Int 1999;41:341-345.

30. Jeong P, Kim EJ, Kim EG, Byun SS, et al. Association of bladder tumors and GA genotype of -308 nucleotide in tumor necrosis factor-alpha promoter with greater tumor necrosis factor-alpha expression. Urology 2004;64:1052-1056.

31. Gonzalez S, Rodrigo L, Martinez-Borra J, Lopez-Vazquez A, et al. TNF-alpha -308A promoter polymorphism is associated with enhanced TNF-alpha production and inflammatory activity in Crohn's patients with fistulizing disease. Am J Gastroenterol 2003;98:1101-1106.

32. Hedberg CL, Adcock K, Martin J, Loggins J, et al. Tumor necrosis factor alpha-308 polymorphism associated with increased sepsis mortality in ventilated very low birth weight infants. Pediatr Infect Dis J 2004;23:424-428.

33. McGuire W, Hill AV, Allsopp CE, Greenwood BM, et al. Variation in the TNFalpha promoter region associated with susceptibility to cerebral malaria. Nature 1994;371:508-510.

34. Cabrera M, Shaw MA, Sharples C, Williams H, et al. Polymorphism in tumor necrosis factor genes associated with mucocutaneous leishmaniasis. J Exp Med 1995;182:1259-1264.

35. Kirkpatrick A, Bidwell J, van den Brule AJ, Meijer CJ, et al. TNFalpha polymorphism frequencies in HPV-associated cervical dysplasia. Gynecol Oncol 2004;92: 675-679.

36. Roberts AK, Monzon-Bordonaba F, Van Deerlin PG, Holder J, et al. Association of polymorphism within the promoter of the tumor necrosis factor alpha gene with increased risk of preterm premature rupture of the fetal membranes. Am J Obstet Gynecol 1999;180:1297-1302.

37. Wilson AG, di Giovine FS, Blakemore AI, Duff GW. Single base polymorphism in the human tumour necrosis factor alpha (TNF alpha) gene detectable by NcoI restriction of PCR product. Hum Mol Genet 1992;1:353.

38. Simhan HN, Krohn MA, Zeevi A, Daftary A, et al. Tumor necrosis factor-alpha promoter gene polymorphism -308 and chorioamnionitis. Obstet Gynecol 2003; 102:162-166

39. Moore S, Ide M, Randhawa M, Walker JJ, et al. An investigation into the association among preterm birth, cytokine gene polymorphisms and periodontal disease. BJOG 2004;111:125-132.

40. Dizon-Townson DS, Major H, Varner M, Ward K. A promoter mutation that increases transcription of the tumor necrosis factor-alpha gene is not associated with preterm delivery. Am J Obstet Gynecol 1997;177:810-813.

41. Dizon-Townson DS. Preterm labour and delivery: a genetic predisposition. Paediatr Perinatal Epidemiol 2001;15 Supplement:(Suppl 2):57-62.

42. Aidoo M, McElroy PD, Kolczak MS, Terlouw DJ, et al. Tumor necrosis factoralpha promoter variant 2 (TNF2) is associated with pre-term delivery, infant mortality, and malaria morbidity in western Kenya: Asembo Bay Cohort Project IX. Genet Epidemiol 2001;21:201-211.

43. Chen D, Hu Y, Wu B, Chen L, et al. Tumor necrosis factor-alpha gene G308A polymorphism is associated with the risk of preterm delivery. Beijing Da Xue Xue Bao 2003;35:377-381.

44. Endres LK, Wang EY. Relationship between tumor necrosis factor-alpha genotype and success of emergent cerclage. Am J Perinatol 2003;20:109-113.

45. Hassan MI, Aschner Y, Manning CH, Xu J, et al. Racial differences in selected cytokine allelic and genotypic frequencies among healthy, pregnant women in North Carolina. Cytokine 2003;21:10-16.

46. Sadowsky DW, Novy MJ, Witkin SS, Gravett MG. Dexamethasone or interleukin-10 blocks interleukin-1beta-induced uterine contractions in pregnant rhesus monkeys. Am J Obstet Gynecol 2003;188:252-263.

47. Dinarello CA. Interleukin-1 and interleukin-1 antagonism. Blood 1991;77:16271652.

48. Arend WP. Interleukin 1 receptor antagonist. A new member of the interleukin 1 family. J Clin Invest 1991;88:1445-1451.

49. Witkin SS, Gravett MG, Haluska GJ, Novy MJ. Induction of interleukin-1 receptor antagonist in rhesus monkeys after intraamniotic infection with group B streptococci or interleukin-1 infusion. Am J Obstet Gynecol 1994;171:1668-1672.

50. Hurme M, Santtila S. IL-1 receptor antagonist (IL-1Ra) plasma levels are co-ordinately regulated by both IL-1Ra and IL-1beta genes. Eur J Immunol 1998;28:25982602.

51. Padyukov L, Lampa J, Heimburger M, Ernestam S, et al. Genetic markers for the efficacy of tumour necrosis factor blocking therapy in rheumatoid arthritis. Ann Rheum Dis 2003;62:526-529.
52. Genc MR, Gerber S, Nesin M, Witkin SS. Polymorphism in the interleukin-1 gene complex and spontaneous preterm delivery. Am J Obstet Gynecol 2002;187:157163.

53. Kalish RB, Vardhana S, Gupta M, Chasen ST, et al. Interleukin-1 receptor antagonist gene polymorphism and multifetal pregnancy outcome. Am J Obstet Gynecol 2003;189:911-914.

54. Witkin SS, Vardhana S, Yih M, Doh K, et al. Polymorphism in intron 2 of the fetal interleukin-1 receptor antagonist genotype influences midtrimester amniotic fluid concentrations of interleukin-1beta and interleukin-1 receptor antagonist and pregnancy outcome. Am J Obstet Gynecol 2003;189:1413-1417.

55. Weiyuan Z, Li W. Study of interleukin-6 and tumor necrosis factor-alpha levels in maternal serum and amniotic fluid of patients with premature rupture of membranes. J Perinat Med 1998;26:491-494.

56. Rizzo G, Capponi A, Vlachopoulou A, Angelini E, et al. Interleukin-6 concentrations in cervical secretions in the prediction of intrauterine infection in preterm premature rupture of the membranes. Gynecol Obstet Invest 1998;46:91-95.

57. Romero R, Avila C, Santhanam U, Sehgal PB. Amniotic fluid interleukin 6 in preterm labor. Association with infection. J Clin Invest 1990;85:1392-1400.

58. Fishman D, Faulds G, Jeffery R, Mohamed-Ali V, et al. The effect of novel polymorphisms in the interleukin-6 (IL-6) gene on IL-6 transcription and plasma IL-6 levels, and an association with systemic-onset juvenile chronic arthritis. J Clin Invest 1998;102:1369-1376.

59. Cox ED, Hoffmann SC, DiMercurio BS, Wesley RA, et al. Cytokine polymorphic analyses indicate ethnic differences in the allelic distribution of interleukin-2 and interleukin-6. Transplantation 2001;72:720-726.

60. DeMichele A, Martin AM, Mick R, Gor P, et al. Interleukin-6-174G->C polymorphism is associated with improved outcome in high-risk breast cancer. Cancer Res 2003;63:8051-8056.

61. Simhan HN, Krohn MA, Roberts JM, Zeevi A, et al. Interleukin-6 promoter-174 polymorphism and spontaneous preterm birth. Am J Obstet Gynecol 2003;189: 915-918.

62. Hoffmann SC, Stanley EM, Cox ED, DiMercurio BS, et al. Ethnicity greatly influences cytokine gene polymorphism distribution. Am J Transplant 2002;2:560-567.

63. Saito S, Sakai M, Sasaki Y, Tanebe K, et al. Quantitative analysis of peripheral blood Th0, Th1, Th2 and the Th1:Th2 cell ratio during normal human pregnancy and preeclampsia. Clin Exp Immunol 1999;117:550-555.

64. Hunt PJ, Marshall SE, Weetman AP, Bell JI, et al. Cytokine gene polymorphisms in autoimmune thyroid disease. J Clin Endocrinol Metab 2000;85:1984-1988.

65. Kawashima T, Noguchi E, Arinami T, Yamakawa-Kobayashi K, et al. Linkage and association of an interleukin 4 gene polymorphism with atopic dermatitis in Japanese families. J Med Genet 1998;35:502-504.

66. Kalish RB, Vardhana S, Gupta M, Perni SC, et al. Interleukin-4 and -10 gene polymorphisms and spontaneous preterm birth in multifetal gestations. $\mathrm{Am} \mathrm{JOb}$ stet Gynecol 2004;190:702-706.

67. Tower GB, Coon CI, Brinckerhoff CE. The $2 \mathrm{G}$ single nucleotide polymorphism (SNP) in the MMP-1 promoter contributes to high levels of MMP-1 transcription in MCF-7/ADR breast cancer cells. Breast Cancer Res Treat 2003;82:75-82.

68. Ye S, Gale CR, Martyn CN. Variation in the matrix metalloproteinase-1 gene and risk of coronary heart disease. Eur Heart J 2003;24:1668-1671.

69. Jones GT, Phillips VL, Harris EL, Rossaak JI, et al. Functional matrix metalloproteinase-9 polymorphism (C-1562T) associated with abdominal aortic aneurysm. Vasc Surg 2003;38:1363-1367.

70. Morgan AR, Zhang B, Tapper W, Collins A, et al. Haplotypic analysis of the MMP-9 gene in relation to coronary artery disease. J Mol Med 2003;81:321-326.

71. Minematsu N, Nakamura H, Tateno H, Nakajima T, et al. Genetic polymorphism in matrix metalloproteinase-9 and pulmonary emphysema. Biochem Biophys Res Commun 2001;289:116-119.

72. Maymon E, Romero R, Pacora P, Gervasi MT, et al. Evidence for the participation of interstitial collagenase (matrix metalloproteinase 1) in preterm premature rupture of membranes. Am J Obstet Gynecol 2000;183:914-920.

73. Maymon E, Romero R, Pacora P, Gervasi MT, et al. Evidence of in vivo differential bioavailability of the active forms of matrix metalloproteinases 9 and 2 in parturition, spontaneous rupture of membranes, and intra-amniotic infection. Am J Obstet Gynecol 2000;183:887-894.

74. McLaren J, Taylor DJ, Bell SC. Increased concentration of pro-matrix metalloproteinase 9 in term fetal membranes overlying the cervix before labor: implications for membrane remodeling and rupture. Am J Obstet Gynecol 2000;182:409-416.

75. Blackmore CA, Savitz DA, Edwards LJ, Harlow SD, et al. Racial differences in the patterns of preterm delivery in central North Carolina, USA. Paediatr Perinat Epidemiol 1995;9:281-295.

76. Fujimoto T, Parry S, Urbanek M, Sammel M, et al. A single nucleotide polymorphism in the matrix metalloproteinase-1 (MMP-1) promoter influences amnion cell MMP-1 expression and risk for preterm premature rupture of the fetal membranes. J Biol Chem 2002;277:6296-6302. 


\section{Crider et al}

77. Koivunen E, Saksela O, Itkonen O, Osman S, et al. Human colon carcinoma, fibrosarcoma and leukemia cell lines produce tumor-associated trypsinogen. Int $J$ Cancer 1991;47:592-596.

78. Kondapaka SB, Fridman R, Reddy KB. Epidermal growth factor and amphiregulin up-regulate matrix metalloproteinase-9 (MMP-9) in human breast cancer cells. Int J Cancer 1997;70:722-726.

79. Romero R, Chaiworapongsa T, Espinoza J, Gomez R, et al. Fetal plasma MMP-9 concentrations are elevated in preterm premature rupture of the membranes. Am J Obstet Gynecol 2002;187:1125-1130.

80. Ferrand PE, Parry S, Sammel M, Macones GA, et al. A polymorphism in the matrix metalloproteinase- 9 promoter is associated with increased risk of preterm premature rupture of membranes in African Americans. Mol Hum Reprod 2002;8:494501.

81. Nelissen I, Vandenbroeck K, Fiten P, Hillert J, et al. Polymorphism analysis suggests that the gelatinase $\mathrm{B}$ gene is not a susceptibility factor for multiple sclerosis. $J$ Neuroimmunol 2000;105:58-63.

82. Beutler B, Poltorak A. Sepsis and evolution of the innate immune response. Crit Care Med 2001;29:S2-S6.

83. Tal G, Mandelberg A, Dalal I, Cesar K, et al. Association between common Toll-like receptor 4 mutations and severe respiratory syncytial virus disease. J Infect Dis 2004;189:2057-2063.

84. Agnese DM, Calvano JE, Hahm SJ, Coyle SM, et al. Human toll-like receptor 4 mutations but not CD14 polymorphisms are associated with an increased risk of gram-negative infections. J Infect Dis 2002;186:1522-1525.

85. Lorenz E, Hallman M, Marttila R, Haataja R, et al. Association between the Asp299Gly polymorphisms in the toll-like receptor 4 and premature births in the Finnish population. Pediatr Res 2002;52:373-376.

86. Liu YL, Nwosu UC, Rice PJ. Relaxation of isolated human myometrial muscle by beta2-adrenergic receptors but not betal-adrenergic receptors. Am J Obstet Gynecol 1998;179:895-898.

87. Iams JD. The role of tocolysis in the prevention of preterm birth. Birth 1996;23:40 41.

88. Madden KS, Sanders VM, Felten DL. Catecholamine influences and sympathetic neural modulation of immune responsiveness. Annu Rev Pharmacol Toxicol 1995; 35:417-448.

89. Elenkov IJ, Chrousos GP, Wilder RL. Neuroendocrine regulation of IL-12 and TNF-alpha/IL-10 balance. Clinical implications. Ann N Y Acad Sci 2000;917:94105: 94-105.

90. Kalinichenko VV, Mokyr MB, Graf LH, Cohen RL, et al. Norepinephrine-mediated inhibition of antitumor cytotoxic T lymphocyte generation involves a betaadrenergic receptor mechanism and decreased TNF-alpha gene expression. J Immunol 1999;163:2492-2499.

91. Gao H, Sun Y, Wu Y, Luan B, et al. Identification of beta-arrestin2 as a G proteincoupled receptor-stimulated regulator of NF-kappaB pathways. Mol Cell 2004;14: 303-317.

92. Reihsaus E, Innis M, MacIntyre, N, Liggett SB. Mutations in the gene encoding for the beta 2-adrenergic receptor in normal and asthmatic subjects. Am J Respir Cell Mol Biol 1993;8:334-339.

93. Leineweber K, Brodde OE. Beta2-adrenoceptor polymorphisms: relation between in vitro and in vivo phenotypes. Life Sci 2004;74:2803-2814.

94. Turki J, Pak J, Green SA, Martin RJ, et al. Genetic polymorphisms of the beta 2-adrenergic receptor in nocturnal and nonnocturnal asthma. Evidence that Gly16 correlates with the nocturnal phenotype. J Clin Invest 1995;95:1635-1641.

95. Large V, Hellstrom L, Reynisdottir S, Lonnqvist F, et al. Human beta-2 adrenoceptor gene polymorphisms are highly frequent in obesity and associate with altered adipocyte beta-2 adrenoceptor function. J Clin Invest 1997;100:3005-3013.

96. Corbalan MS. The 27Glu polymorphism of the beta2-adrenergic receptor gene interacts with physical activity influencing obesity risk among female subjects. Clin Genet 2002;61:305-307.

97. Green SA, Turki J, Innis M, Liggett SB. Amino-terminal polymorphisms of the human beta 2-adrenergic receptor impart distinct agonist-promoted regulatory properties. Biochemistry 1994;33:9414-9419.

98. Landau R, Xie HG, Dishy V, Stein CM, et al. beta2-Adrenergic receptor genotype and preterm delivery. Am J Obstet Gynecol 2002;187:1294-1298.
99. Ozkur M, Dogulu F, Ozkur A, Gokmen B, et al. Association of the Gln27Glu polymorphism of the beta-2-adrenergic receptor with preterm labor. Int J Gynaecol Obstet 2002;77:209-215.

100. Ruhrberg C. Growing and shaping the vascular tree: multiple roles for VEGF. Bioessays 2003;25:1052-1060.

101. Awata T, Inoue K, Kurihara S, Ohkubo T, et al. A common polymorphism in the 5 '-untranslated region of the VEGF gene is associated with diabetic retinopathy in type 2 diabetes. Diabetes 2002;51:1635-1639.

102. Papazoglou D, Galazios G, Koukourakis MI, Kontomanolis EN, et al. Association of $-634 \mathrm{G} / \mathrm{C}$ and $936 \mathrm{C} / \mathrm{T}$ polymorphisms of the vascular endothelial growth factor with spontaneous preterm delivery. Acta Obstet Gynecol Scand 2004;83:461-465.

103. Klerk M, Verhoef P, Clarke R, Blom HJ, et al. MTHFR 677C->T polymorphism and risk of coronary heart disease: a meta-analysis. JAMA 2002;288:2023-2031.

104. Botto LD, Yang Q. 5,10-Methylenetetrahydrofolate reductase gene variants and congenital anomalies: a HuGE review. Am J Epidemiol 2000;151:862-877.

105. Robien K, Ulrich CM. 5,10-Methylenetetrahydrofolate reductase polymorphisms and leukemia risk: a HuGE minireview. Am J Epidemiol 2003;157:571-582.

106. Lauszus FF, Gron PL, Klebe JG. Association of polymorphism of methylene-tetrahydro-folate-reductase with urinary albumin excretion rate in type 1 diabetes mellitus but not with preeclampsia, retinopathy, and preterm delivery. Acta Obstet Gynecol Scand 2001;80:803-806.

107. Camilleri RS, Peebles D, Portmann C, Everington T, et al. -455G/A beta-fibrinogen gene polymorphism, factor V Leiden, prothrombin G20210A mutation and MTHFR C677T, and placental vascular complications. Blood Coagul Fibrinolysis 2004;15:139-147.

108. Wuthrich RP. Factor V Leiden mutation: potential thrombogenic role in renal vein, dialysis graft and transplant vascular thrombosis. Curr Opin Nephrol Hypertens 2001;10:409-414

109. Morrison ER, Miedzybrodzka ZH, Campbell DM, Haites NE, et al. Prothrombotic genotypes are not associated with pre-eclampsia and gestational hypertension: results from a large population-based study and systematic review. Thromb Haemost 2002;87:779-785.

110. Hao K, Wang X, Niu T, Xu X, et al. A candidate gene association study on preterm delivery: application of high-throughput genotyping technology and advanced statistical methods. Hum Mol Genet 2004;13:683-691. Epub 2004 Feb 19.

111. Ambrose JA, Barua RS. The pathophysiology of cigarette smoking and cardiovascular disease: an update. J Am Coll Cardiol 2004;43:1731-1737.

112. Hernandez-Guerrero C, Monzon-Bordonaba F, Jimenez-Zamudio L, AhuedAhued R, et al. In-vitro secretion of proinflammatory cytokines by human amniochorion carrying hyper-responsive gene polymorphisms of tumour necrosis factor-alpha and interleukin-1beta. Mol Hum Reprod 2003;9:625-629.

113. Macones GA, Parry S, Elkousy M, Clothier B, et al. A polymorphism in the promoter region of TNF and bacterial vaginosis: preliminary evidence of gene-environment interaction in the etiology of spontaneous preterm birth. Am J Obstet Gynecol 2004;190:1504-1508.

114. Romero R, Chaiworapongsa T, Kuivaniemi H, Tromp G. Bacterial vaginosis, the inflammatory response and the risk of preterm birth: a role for genetic epidemiology in the prevention of preterm birth. Am J Obstet Gynecol 2004;190:1509-1519.

115. Khanna D, McMahon M, Furst DE. Safety of tumour necrosis factor-alpha antagonists. Drug Saf 2004;27:307-324.

116. West SL, Yawn BP, Thorp JM, Korhonen MJ, et al. Tocolytic therapy for preterm labour: assessing its potential for reducing preterm delivery. Paediatr Perinat Epidemiol 2001;15:243-251.

117. Goldenberg RL, Culhane JF. Infection as a cause of preterm birth. Clin Perinatol 2003;30:677-700

118. Goldenberg RL, Iams JD, Mercer BM, Meis P, et al. What we have learned about the predictors of preterm birth. Semin Perinatol 2003;27:185-193.

119. Meis PJ, Klebanoff M, Thom E, Dombrowski MP, et al. Prevention of recurren preterm delivery by 17 alpha-hydroxyprogesterone caproate. N Engl J Med 2003; 348:2379-2385.

120. da Fonseca EB, Bittar RE, Carvalho MH, Zugaib M. Prophylactic administration of progesterone by vaginal suppository to reduce the incidence of spontaneous preterm birth in women at increased risk: a randomized placebo-controlled doubleblind study. Am J Obstet Gynecol 2003;188:419-424. 